containers for reactions. Among the more virtuoso syntheses are ring-like molecules that are linked together (including, inevitably, olympane, in which five rings are linked) and large rings that act like railways on which other rings race around, with benzene rings on the track acting like stations. Chemists can emulate ion channels, and, who knows, may one day be able to build a neuron and even a fully organic computer. Already they can emulate biological membranes and, through the construction of special gels and colloids, have built materials that respond to external fields. Thus they can simulate muscles that contract and relax in response to electric fields and make materials that respond similarly to light. Such innovations may prove to be of use in drug delivery, where the casing of a drug may respond to changes in acidity and deliver its load where it is required.

Readers of this book will come away with a clear impression of chemistry's profound and serious contribution to the modern world and of its awesome potential. I recommend it warmly, especially to those on the brink of wondering whether to enter chemistry as a career. They will see the limitlessness of its horizons.

Peter Atkins is at Lincoln College, Oxford OX1 3DR, UK.

\section{What's love got to do with it?}

\section{Jeffrey Weeks}

Science in the Bedroom: A History of Sex Research. By Vern L. Bullough. BasicBooks: 1994. Pp. 376. \$25.

I FIRST encountered the work of Vern Bullough in what, for lack of a better word, I can only describe as a seminal essay, Sex in History: A Virgin Field, first published in 1972. Just as sociologists were then beginning to define a gross absence in social scientific endeavour the lack of serious study of human sexuality that was more than 'social bookkeeping' (who does what to whom and when) - so historians such as Bullough were observing and deploring the silences of the history texts. Only 20 years ago, serious sociological or historical study of sexuality made one, in Ken Plummer's phrase, "morally suspect". That this is less true today is due in large part to the pioneering work of researchers such as Bullough.

Science in the Bedroom surveys what has become a key area for investigation, the role of sex research or sexology itself. The sexological pioneers at the end of the nineteenth and the beginning of the twen- tieth century saw themselves as engaged in a classically Enlightenment endeavour: to uncover the 'laws of nature' that governed sexual behaviour, to classify its diverse patterns, to establish the rules of normality and abnormality, and thereby to inform public debate. As Bullough notes, pioneers such as Richard von KrafftEbing were at least in part encouraged to

\section{IMAGE UNAVAILABLE FOR COPYRIGHT REASONS}

\section{Sex psychologist: Havelock Eilis.}

begin their work by the exigencies of forensic medicine. Others such as Ulrichs or Havelock Ellis also had a more political purpose: to provide a more scientific basis to the laws relating to sexuality so that they could be developed in a less moralistic fashion. Bullough rightly pinpoints the importance of the debate on homosexuality to these early sexologists. Homosexuality was a puzzle because it was a cross-cultural and trans-historical phenomenon, acceptable in some forms in some societies and execrated in others, that was startlingly similar to heterosexual forms (object-choice, falling in love, the basis for established relationships and so on); and yet it did not fit easily into the prevailing models of sex as geared to reproduction. Magnus Hirschfeld, the great German sexologist and sex reformer, noted that more than a thousand articles on homosexuality were published between 1895 and 1910 - many of them from his pen. Homosexuality then, as now, provided a litmus test for theories of sexuality, and for the rationality of the legal framework. Hirschfeld's institute for sexual science in Berlin had inscribed above its portals the slogan "Through science to justice", a noble aim unfortunately soon after obliterated by the Nazi onslaught on reason.

More recently, however, this progressive consensus has been subject to attack. Some sexual scientists turned out not to be particularly progressive, especially with regard to homosexuality. More fundamentally, the role of sexology has itself been challenged. The works of Michel Foucault and others have asserted the constitutive role of sexology, not so much describing and anatomizing the various forms of desire as constructing their importance. Again, homosexuality is a limit case: the new social history has illustrated particularly the way in which the categorization of homosexuality helped to shape the emergence of distinctive homosexual identities from the nineteenth century, with homosexuality seen as the essence of a particular type of person. Sexology, in other words, was complicit with the forms of power and knowledge that imposed definitions as much as they freed human sexual potential. Feminist scholars have similarly sought to show how the apparently liberal views of sexologists actually enforced 'compulsory heterosexuality' on women. Alongside this, a sort of 'grass-roots' sexology has emerged among sexual radicals, emphasizing the importance of self-definition, self-making and self-help often against the nostrums of the would-be scientists of desire. In other words, the hegemony of scientific sex research - even of science itself under the postmodernist onslaught - has been radically challenged.

Bullough's book urbanely scans this fervent sexual-ideological landscape, and will be an extremely useful text for both the general reader and the student. It is a worthy climax to his pioneering work, no longer tilling virgin ground but fertilizing a flourishing landscape. My criticism is that although he provides much of the necessary evidence, his study does not directly tackle the critiques of sexology that I have indicated above. He judiciously measures achievements and failures, but does so within the terms of the sex researchers themselves, treating the scientific endeavour as a noble cause of enlightenment. This certainly accords, as I have indicated, with the self-image of the pioneers, and of their successors, from Freud to Kinsey and beyond. And it would be wrong to deny the achievements of sexology: what we know today about the body, its complicated forms of expression, the role of the mind in shaping sexual expression, and the influence of culture in patterning sexual identities, has been fundamentally shaped by the diligence of sex researchers. But as this list indicates, knowledge of sexual processes does not necessarily tell us how unruly individuals and groups will behave. Sex research in the end is useful only if closely linked to an appreciation of historical and cultural processes. A full history of sex research needs to put these wider processes at its heart. Science in the Bedroom has great merits, but there is still a lot of work to be done if we are to understand fully the problematic nature and role of sex research.

Jeffrey Weeks is in the Faculty of Economics and Social Science, University of the West of England, Coldharbour Lane, Frenchay, Bristol BS16 1QY, UK. 